\title{
Hepatoprotective Effects of Various Solvent Extracted Samples of Paeonia Emodi (wall) in Mice with Paracetamol-Induced Hepatotoxicity
}

\author{
Liaqat Zeb (Corresponding Author) \\ Doctor of Philosophy Student, School of Life Science and Biotechnology, \\ Dalian University of Technology, Dalian, China. E-mail: Liaqatzeb@ dlut.edu.cn \\ E-mail: Liaqatzeb135@gmail.com \\ Muhammad Shafiq \\ Doctor of Philosophy student, School of Life Science and Biotechnology, \\ Dalian University of Technology, Dalian, China. E-mail: mshafiq.biotech@gmail.com
}

Asaf Khan

Doctor of Philosophy student, School of Life Science,

Sun Yat-sen University, Guangzhou, China. E-mail: asafkhan07@gmail.com

Ali Akbar

Doctor of Philosophy student, School of Science,

Liaoning University, Shenyang, China. E-mail: aliswatian77@gmail.com

\section{Ishfaq Ahmad}

Doctor of Philosophy student, College of Life Sciences,

Capital Normal University, Beijing, China. E-mail: Ishnew147@yahoo.com

\section{Abdul Majid}

Doctor of Philosophy student, College of Life Sciences,

Capital Normal University, Beijing, China. E-mail: 4160838003@cnu.edu.cn 
Received: May 16, 2017

Accepted: June 8, 2017

doi:10.5296/jbls.v9i2.12974

URL: https://doi.org/10.5296/jbls.v9i2.12974

\begin{abstract}
The goal of present study is to evaluate and recognize the most effective hepatoprotective solvent fractions of methanolic extract of Paeonia emodi by fractionating and assessing its fractions for hepatoprotective effect in paracetamol-induced liver damage in mice. In this study, some liver-related serum parameters such as AST, ALP, and ALT were studied. Maximum reduction was caused by aqueous extract $(61.08 \%)$ followed by a butanol extract $(60.26 \%)$, chloroform extract (48.76\%), crude extract (45.48\%) and drug (37.93\%), in case of ALT. During the study of AST, chloroform extract caused a maximum reduction (65.94\%), followed by a butanol extract $(60.43 \%)$, aqueous extract $(57.13 \%)$, crude extract $(57.13 \%)$ and drug (43.94\%). During the study of ALP aqueous fraction caused a maximum reduction (47.22 \%), followed by a butanol fraction (44.44\%), chloroform (41.51\%), methanol extract $(34.72 \%)$ and drug $(20.83 \%)$. In all the treatment groups the serum levels of ALT, AST and ALP were significantly lower as compared to those of untreated controlled group $(\mathrm{P}<0.05)$. The present research showed that Paeonia emodi has the potential to reduce paracetamol-induced hepatotoxicity in mice and restore the normal liver function.
\end{abstract}

Keywords: Hepatoprotective, Paeonia emodi, extracts, ALP, AST, ALT

\title{
1. Introduction
}

The liver is the largest internal reddish-brown organ in the human body. A Typical human liver weighs between 1.1 and $1.7 \mathrm{~kg}$. The liver is a highly vascular and dynamic organ. One of its main vascular functions is to act as a blood reservoir. The liver's unique vascular structure serves as a blood filter. Metabolically the liver is responsible for controlling the synthesis, utilization, and storage of carbohydrates, proteins, fats, and vitamins and for detoxifying metabolic waste products and toxins that enter the body (Burkitt et al., 1997). The liver is also responsible for the production and secretion of bile to aid in digestion (bile is salt that emulsifies fats so that they are easier to digest) (Guyton and Hall, 1996). The liver has the unique capability of regeneration; whether injured or a small piece removed, the liver seems capable of unlimited proliferation to meet the demands of its body (Brown, 1997). It has an important target of toxicity to xenobiotic, oxidative stress and toxic chemicals (Patel et al., 2009). Damage to the liver inflicted by hepatotoxic agents is of grave consequences. Liver damage occurs due to exposure to toxic chemicals, excessive use of alcohol, infections such as hepatitis A, B, C, D, E, fats accumulation, cancer, and drugs. Chemicals such as acetaminophen (PCM), tetracycline, ethanol and carbon tetrachloride induce lipid peroxidation, damage the membranes of liver cells and organelles, cause the swelling and necrosis of hepatocytes and result in the release of cytosolic enzymes such as Alanine transaminase (ALT), Aspartate transaminase (AST) and Alkaline phosphatase (ALP) into the blood circulation (Shaaraway et al., 2009). 
Alanine transaminase (ALT) is also called glutamate pyruvate transaminase (GPT). This enzyme catalyzes transamination reaction. Transamination is the major process for the removal of nitrogen from amino acids. In most instances the nitrogen is transferred as an amino group from the original amino acid to $\alpha$-ketoglutarate, forming glutamate, while the original amino acid is converted to its corresponding $\alpha$-keto acid. For most of these reactions, $\alpha$-ketoglutarate and glutamate serve as one of the $\alpha$-keto acid-amino acid pairs. Pyridoxal phosphate acts as a cofactor. Overall these reactions are involved both in the amino acid degradation and in amino acid synthesis.

Ammonia in the form of the amino acid alanine is transported to the liver. Alanine is synthesized in the muscle tissue by a transamination reaction between pyruvate and glutamate. Alanine is then transported through the bloodstream to the liver where it reacts with $\alpha$-ketoglutarate to form pyruvate and glutamate. The reaction is catalyzed by alanine transaminase (ALT). The nitrogen originating from the glutamate is processed by the urea cycle. When the blood glucose concentration is low, the pyruvate resulting from alanine transamination is used to make glucose via gluconeogenesis pathway. The glucose can be returned to skeletal muscle to supply quick energy. ALT is produced and localized in the hepatic cells and their level is increased in the circulation when the hepatic cells are damaged. In tissues, serum ALT occurs in two locations, the cytosol, and mitochondria (Rej, 1978). Serum ALT is a more specific enzyme for liver damage and therefore a high level of this enzyme indicates liver damage (Himmerich et al., 2001).

Aspartate transaminase (AST) also called glutamic oxaloacetic transaminase (GOT). This is pyridoxal phosphate (PLP)-dependent transaminase enzyme which catalyzes the reversible transfer of an $\alpha$-amino group between aspartate and glutamate, and interconversion of aspartate and $\alpha$-ketoglutarate to oxaloacetate and glutamate (Almo et al., 1994). In healthy human adults, this enzyme is mainly derived from liver, heart, skeletal muscle and in a lesser amount from kidneys, brain, and red blood cells. Aspartate transaminase is commonly measured clinically as a part of diagnostic liver function tests, to determine liver health (Nalpas et al., 1986). Dramatic elevation in serum AST indicates liver damage. Serum AST level also increases due to damage to various other tissues and organs.

Alkaline phosphatases comprise a group of enzymes that catalyze the hydrolysis of a number of phosphate esters, in an alkaline environment, generating an organic radical and inorganic phosphate. Alkaline phosphatase is a membrane-bound metalloenzyme comprising a group of isoenzymes encoded by at least four different gene loci (Afonja and Baron, 1974). In healthy adults, this enzyme is mainly derived from the liver, bones and in a lesser amount from the intestine, placenta, kidneys, and leukocytes (Friedman, 1996). The two major and clinically most relevant isoenzymes in human serum are bone and liver alkaline phosphatases formed through post-translational modifications of the tissue non-specific gene product and they mainly circulate insoluble dimeric forms (Tillyer, 1994).

The primary clinical utility of alkaline phosphatase is in cases of suspected bone disorders and obstructive liver diseases. Raised serum levels are seen in different bone disorders including Paget's disease, osteomalacia, rickets, hyperparathyroidism, osteogenic sarcoma, 
fractures and osteoblastic metastases. Increased serum levels are also seen in liver disease associated with extra or intrahepatic obstruction, obstructive jaundice, diabetes, infectious mononucleosis, biliary cirrhosis and cholestasis (Kechrid and Kenouz, 2003).

Many clinically useful drugs can cause cellular damage after metabolic activation to highly reactive compounds. One of the commonly used over-the-counter analgesics is paracetamol (PCM). Paracetamol is a drug of the para-aminophenol group, which is considered quite safe at recommended doses and is commonly used in humans to relieve mild to moderate pain, as well as to reduce fever (Meotti et al., 2006). The main problem with this medication is misuse through intentional or unintentional ingestion of supratherapeutic dosages, which usually lead to hepatic necrosis. When administered at normal doses, PCM is primarily metabolized by conjugation with sulfate and glucuronic acid. A minor pathway through CYP450 has also been reported to yield a highly reactive metabolite, $N$-acetyl-p-benzoquinone imine (NAPQI). This metabolite is generally stabilized through conjugation with glutathione (GSH) and eliminated via the kidney. However, when an overdose of PCM is administered, the production of NAPQI overloads the capacity of GSH to detoxify it. The excess NAPQI then causes liver damage associated with oxidative stress. Paracetamol overdose is also known to be associated with inflammation, marked by an increase in the inflammatory cytokines; tumor necrosis- $a$ (TNF- $a$ ), interleukin- $1 a$ and interleukin- $1 b$, as well as the upregulation of nitrogen oxide (NO) from serum, macrophages and hepatocytes (Jaeschke et al., 2003; Ghosh et al., 2010) Oxidative stress is reported to constitute a major mechanism in the pathogenesis of PCM-induced liver and renal damage in experimental animals (Ghosh et al., 2010).

Many plants have been reported for their hepatoprotective activities. These include Litchi chinensis Sonn (Basu et al., 2012), Ardisia solanacea (Samal, 2013), Cestrum parqui (Linn) (Rashed et al., 2013), Ocimum americanum (Linn) (Aluko et al., 2012) ,Urtica dioica (Linn) (Kataki et al., 2012), Mentha arvensis (Linn), Amorphophallus paeoniifolius (Hurkadale et al., 2012), Homalium zeylanicum, Vitis vinifera, Ficus carica (Linn), Nilgirianthus ciliates, Gymnosporiaemerginata and Marsedeniavolubillis (Rubab et al., 2013). In Pakistan, there are a wide variety of wild plants which are being used for medicinal and aromatic purposes and many plants have still to be explored for their medicinal values. During the present study, various extracts of Paeonia emodi (Wall) were studied for their hepatoprotective effects in mice with paracetamol-induced hepatotoxicity.

Paeonia emodi is a highly medicinal plant that belongs to family Paeoniaceae, locally known as "Mamekh".It is a perennial herb, $70 \mathrm{~cm}$ in height, Stem is glabrous, the proximal leaves are two ternate; oblong-elliptic or oblong-lanceolate, both leaf surfaces are glabrous, base cuneate, decurrent and apex acuminate. Petals are generally white and obovate. Seeds are black in color and globose. The flowering time is May and June in the Himalayan range (Haq et al., 2012). It is widely distributed in Northern Himalayan region of Pakistan, India, Nepal, and China (Khan et al., 2005). P. emodi has been used for a long time in the traditional medical system. The roots and rhizomes are locally used as the best remedy for a backache, dropsy, and epilepsy. It is also used traditionally as a tonic energizer, emetic, cathartic, blood purifier, and colic. The seeds are used as purgative. 


\section{Macrothink

Various valuable compounds have been isolated from this plant including oleanolic acid, ethyl gallate, methyl Greville, betulinic acid and 1, 5-dihydroxy-3-methylanthraquinone (Nawaz et al., 2000). Other constituents extracted from this plant are; monoterpene glycosides, wording, and benzoylwurdin along with lactoferrin, paeoniflorin, and oxy-paeoniflorin (Muhammad et al., 1999). Emodinol is an important constituent of this plant which is an oleane type triterpene, having substantial glucuronidase inhibitory action. Benzoic acid and 3-hydroxybenzoic acids are also reported in it. Paeonins A and B, monoterpene galactosides isolated from the rhizome are potent chemical compounds with significant lipoxygenase inhibitory activity has also been reported (Riaz et al., 2003).

\section{Materials and Methods}

\subsection{Materials Collection}

The rhizome part of the plant Paeonia emodi (Wall) was collected in Wari valley of District Upper Dir, Khyber Pukhtoon Khwa Pakistan. Grime and dust were removed, washed with distilled water and shade dried at room temperature, then trailed by crunching to coarse powder exhausting an electronic chopper.

\subsection{Extract preparation}

During preparation of extract, 450gram of powder was soaked in $2000 \mathrm{~mL} \mathrm{f} 100 \%$ methanol. The soaking was done in seven days with occasional shaking. The soaked plant material was filtered through Whatman No. 1 filter paper and placed in a beaker, and the further filtrate was then evaporated through rotary evaporator $44^{\circ} \mathrm{C}$. The extract of plant material was obtained in the form of thick paste yielding approximately 170 grams $(37.77 \mathrm{w} / \mathrm{w})$ by weight. The extracts were divided into two portions; one portion was used as a crude sample, and other was fractioned with chloroform, n-butanol, n-hexane and ethyl acetate.

\subsection{Fractionation}

About $80 \mathrm{~g}$ of crude extract was dissolved $180 \mathrm{~mL}$ distilled water in a beaker. This mixture was introduced into a separating funnel and shaken well. Then $180 \mathrm{ml}$ of $\mathrm{n}$-hexane was added to the separating funnel. The upper layer of $n$-hexane was separated and concentrated in a rotary evaporator to obtain the n-hexane fraction. This procedure was repeated 3 times by adding new n-hexane to the aqueous phase and n-hexane layer was collected. The sample was collected under condensed pressure using rotary evaporator at $44^{\circ} \mathrm{C}$. The similar method was followed for n-butanol, chloroform, and ethyl acetate. The amount and percentage yield (w/w) of these fractions has been shown in Table 1 the fractions were stored at $4^{\circ} \mathrm{C}$. 


\section{IIMacrothink}

Journal of Biology and Life Science

ISSN 2157-6076

2018, Vol. 9, No. 2

Table 1. The yield of Fractions from 80 gram of crude methanol extract (100\%) of P. emodi rhizomes

\begin{tabular}{llllll}
\hline Yield & $\begin{array}{l}\text { n-Hexan } \\
\mathrm{e}\end{array}$ & $\begin{array}{l}\text { Chlorofor } \\
\mathrm{m}\end{array}$ & Ethyl acetate & Butanol & Aqueous \\
$\begin{array}{l}\text { Actual } \\
\text { yield } \\
(\mathrm{w} / \mathrm{w})\end{array}$ & $6.2 \mathrm{~g}$ & $23.3 \mathrm{~g}$ & $10 \mathrm{~g}$ & $9.3 \mathrm{~g}$ & $31.6 \mathrm{~g}$ \\
$\begin{array}{l}\text { Percentage } \\
(\%)\end{array}$ & 7.44 & 28.2 & 12.16 & 11.24 & 38.08 \\
\hline
\end{tabular}

\subsection{Animal used}

A total of 28 Swiss albino adult healthy male mice weighing 24-28 grams were purchased from the National Institute of Health, Islamabad. Seven cages were separately arranged, four mice in each cage $\left(5^{\prime \prime} \times 9 " \times 11^{\prime \prime}\right.$ made of steel mesh). Standard rodent food and water access were all time available to mice. In 12:12 light/dark cycle of photoperiod, mice were maintained. Two weeks before starting experiment they were acclimatized.

\subsubsection{Grouping of the used animal}

All mice were randomly allocated into seven groups, 4 mice in each group. For the identity of different mice groups, various color tags were used. The detail of the grouping is described as under:

Group 1: served as healthy control and was orally administered with normal saline for 14 days.

Group 2: served as negative control and received PCM (600 mg/kg body weight) three times on day zero followed by normal saline for 14 consecutive days.

Group 3: served as a positive control group received PCM $(600 \mathrm{mg} / \mathrm{kg}$ b.w, p.o. in $80 \mathrm{uL}$ distilled water) three times on day 0 followed by Silymarin $(100 \mathrm{mg} / \mathrm{kg}$ b.w, p.o. in $50 \mathrm{uL}$ distilled water) for 13 consecutive days.

Group 4: received PCM (600 mg/kg b.w, p.o. in $80 \mathrm{uL}$ distilled water) three times on day 0 followed by methanol extract ( $300 \mathrm{mg} / \mathrm{kg}$ b.w, p.o. suspended in $70 \mathrm{uL}$ distilled water) for 13 consecutive days.

Group 5: received PCM (600 mg/kg b.w, p.o. in $80 \mathrm{uL}$ distilled water) three times on day 0 followed by chloroform fraction $(300 \mathrm{mg} / \mathrm{kg}$ b.w, p.o. suspended in $70 \mathrm{uL}$ distilled water) for 13 consecutive days.

Group 6: received PCM (600 mg/kg b.w, p.o. in $80 \mathrm{uL}$ distilled water) three times on day 0 followed by butanol fraction ( $300 \mathrm{mg} / \mathrm{kg} \mathrm{b.w}$, p.o. suspended in $70 \mathrm{uL}$ distilled water) for 13 consecutive days.

Group 7: received PCM (600 mg/kg b.w, p.o. in $80 \mathrm{uL}$ distilled water) three times on day 0 


\section{1) Macrothink}

Journal of Biology and Life Science

ISSN 2157-6076

2018, Vol. 9, No. 2

followed by aqueous fraction (300 mg/kg b.w, p.o. suspended in $70 \mathrm{uL}$ distilled water) for 13 consecutive days.

\subsubsection{Collection of Blood}

On day 13 approximately $1.5 \mathrm{ml}$ of blood samples were obtained from each mice. All mice were starved for 12 hours, reweighed, and anesthetized with sodium pentobarbital $60 \mathrm{mg} / \mathrm{kg}$ b.w. Then blood samples from each animal were taken by cervical dislocation.

\subsubsection{Isolation of Serum}

Blood was allowed to stand at room temperature for 1 hour; serum was separated by centrifugation at $3000 \mathrm{rpm}$ for $10 \mathrm{~min}$ (Eppendorf 5702R, Germany). Serum was stored at $-20^{\circ} \mathrm{C}$ until assayed.

\subsection{Assessment of Serum Marker Enzymes}

The enzymatic activities of serum alanine transaminase (ALT), aspartate transaminase (AST) and alkaline phosphatase (ALP) were used as biochemical markers for hepatotoxicity. The ALT, AST and ALP activities in serum supernatants were determined using commercially available kits (AMP Diagnostics, Austria) on a UV-visible light spectrophotometer (Agilent 8453).

\subsubsection{Alanine Transaminase (ALT)}

\section{Reagent composition}

Reagent R1 contained tris buffer, pH 7.50 (125mmol/L), L-Alanine (680 mmol/L), and LDH $(\geq 2000 \mathrm{U} / \mathrm{L})$, while reagent $\mathrm{R} 2$ contained $\alpha$-ketoglutarate $(97 \mathrm{mmol} / \mathrm{L})$ and $\mathrm{NADH}(1.1$ $\mathrm{mmol} / \mathrm{L})$.

\section{Procedure}

Four volumes of R1 were mixed with one volume of R2 to make the working reagent. $20 \mu 1$ of serum sample was mixed with $200 \mu \mathrm{l}$ of working reagent, incubated at for $1 \mathrm{~min}$ at $37{ }^{\circ} \mathrm{C}$ in a water bath and the optical density per minute $(\Delta \mathrm{OD} / \mathrm{min})$ was read at $340 \mathrm{~nm}$. The final concentration was determined by the following formula:

$$
\text { Activity }(\mathrm{U} / \mathrm{L})=\Delta \mathrm{OD} / \mathrm{min} \times 1746
$$

\subsubsection{Aspartate Transaminase (AST)}

\section{Reagent composition}

Reagent 1 (R1) contains Tris buffer (pH 7.6) and L.aspartate, Reagent 2 (R2) contains malate dehydrogenase (MDH), Lactate dehydrogenase ( $\mathrm{LDH})$, a-ketoglutarate and NADH. The same procedure was followed as mentioned in 2.5.1. 


\subsubsection{Alkaline Phosphatase (ALP)}

\section{Reagent composition}

Reagent $\mathrm{R} 1$ contained diethanolamine buffer, $\mathrm{pH} 10.2$ (1.25 mol/L) and magnesium chloride $(0.625 \mathrm{mmol} / \mathrm{L})$, while reagent $\mathrm{R} 2$ contained $\mathrm{p}$-Triphenylphosphate $(50 \mathrm{mmol} / \mathrm{L})$. The similar method was employed as mentioned in 2.5.1.

\subsection{Statistical Analysis}

Results are presented as means + Standard deviation of means (SEM), the means were compared by using Tukey Test of Post Hoc Multiple comparisons in One Way ANOVA. For these analysis computers software, SPSS 16.0 was used.

\section{Results}

During the present study, the hepatoprotective effects of methanol extract and chloroform, butanol and aqueous fractions of the rhizome of Paeonia emodi (Wall) were investigated in mice with Paracetamol-induced hepatotoxicity. The enzymatic activities of serum alanine transaminase (ALT), aspartate transaminase (AST) and alkaline phosphatase (ALP) were used as biochemical markers for hepatotoxicity.

\subsection{ALT}

During the study of alanine transaminase, the drug (Silymarin) and the plant extracts caused a reduction in its serum level. Maximum reduction was caused by the aqueous fraction $(61.08 \%)$ followed by butanol fraction $(60.26 \%)$, chloroform fraction $(48.76 \%)$, crude extract (45.48 \%) and drug (37.93\%) (Table 3.1) The effects of P.emodi methanol extract and its various solvent fractions on serum ALT were compared statistically. In all the treatment groups the serum level of ALT was significantly lower as compared to untreated controlled group $(\mathrm{P}<0.05)$. Among the treatment groups, the serum level in aqueous, butanol and chloroform fractions groups was significantly lower as compared to standard group (drug-treated group $)(\mathrm{P}<0.05)$. The standard and crude extract treated groups showed homogeneity in serum ALT level $(\mathrm{P}>0.05)$. Similarly, chloroform and crude extract, and aqueous and butanol fractions treated groups showed homogeneity in serum ALT level (P>0.05) (Table 3.4).

\section{2. $A L P$}

During the study of alkaline phosphatase, the drug (Silymarin) and the plant extracts caused a reduction in its serum level. Aqueous fraction caused maximum reduction (47.22\%), followed by butanol fraction (44.44\%), chloroform (41.51\%), methanol extract $(34.72 \%)$ and drug $(20.83 \%$ ) (Table, 3.2) The effects of P. emodi methanol extract and its various solvent fractions on serum ALP were compared statistically. In all the treatment groups the serum level of ALP was significantly lower as compared to untreated controlled group $(\mathrm{P}<0.05)$. Among the treatment groups, the serum ALP level in extracts treated groups was significantly lower as compared to standard group (drug-treated group $)(\mathrm{P}<0.05)$. Methanol extract and chloroform fraction treated groups showed homogeneity in serum ALP level 


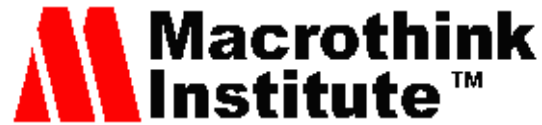

$(\mathrm{P}>0.05)$. Similarly chloroform, butanol and aqueous fractions treated groups showed homogeneity in serum ALP level (P>0.05) (Table 3.4).

\subsection{AST}

During the study of aspartate transaminase, the drug (Silymarin) and the plant extracts caused a reduction in its serum level. Chloroform fraction caused maximum reduction (65.94 \%), followed by butanol fraction (60.43\%), aqueous fraction $(57.13 \%)$, crude extract $(57.13 \%)$ and drug (43.94\%) (Table 3.3). The effects of P.emodi methanol extract and its various solvent fractions on serum AST were compared statistically. In all the treatment groups the serum level of AST was significantly lower as compared to untreated controlled group $(\mathrm{P}<0.05)$. Compared to standard group (drug-treated group), other treatment groups chloroform, butanol, aqueous and crude fractions groups significantly lower serum level $(\mathrm{P}<0.05)$. The standard and various extract treated groups did not show homogeneity in serum AST level $(\mathrm{P}<0.05)$. Chloroform, crude, aqueous and butanol fractions treated groups showed homogeneity in serum AST level (P>0.05) (Table 3.4).

Table 3.1: Effects of two weeks oral administration of various solvent extracts of rhizome part of $P$. emodi on serum ALT level of mice with PCM induced hepatotoxicity

\begin{tabular}{|c|l|c|c|c|}
\hline Groups & Mean & \multirow{2}{*}{ SD } & \multicolumn{2}{|c|}{ 95\% Confidence interval } \\
\cline { 4 - 5 } & & & Lower Bound & Upper Bound \\
\hline Normal control & 15.25 & 3.3 & 11.133 & 19.97 \\
\hline Negative control & 203.00 & 10.000 & 178.16 & 227.84 \\
\hline Drug & $126.00(-37.93 \%)$ & 5.000 & 113.58 & 138.42 \\
\hline Crude & $110.67(-45.48 \%)$ & 5.508 & 96.99 & 124.35 \\
\hline Chloroform & $104.00(-48.76 \%)$ & 5.000 & 91.58 & 116.42 \\
\hline Butanol & $80.67(-60.26 \%)$ & 6.506 & 64.50 & 96.83 \\
\hline Aqueous & $79.00(-61.08 \%)$ & 5.000 & 66.58 & 91.42 \\
\hline
\end{tabular}

PCM, Paracetamol; SD, standard deviation

Table 3.2: Effects of two weeks oral administration of various solvent extracts of rhizome part of $P$. emodi on serum ALP level of mice with PCM induced hepatotoxicity

\begin{tabular}{|c|l|c|c|c|}
\hline Groups & Mean & \multirow{2}{*}{ SD } & \multicolumn{2}{|c|}{ 95\% Confidence interval } \\
\cline { 4 - 5 } & & & Lower Bound & Upper Bound \\
\hline Normal control & 64.75 & 5.7 & 56.12 & 74.4 \\
\hline Negative control & 216.00 & 10.000 & 191.16 & 240.84 \\
\hline Standard & $171.00(-20.83 \%)$ & 6.000 & 190.10 & 219.90 \\
\hline Crude & $141.00(-34.72 \%)$ & 7.000 & 123.61 & 158.39 \\
\hline Chloroform & $126.33(-41.51 \%)$ & 5.132 & 113.59 & 139.08 \\
\hline Butanol & $120.00(-44.44 \%)$ & 7.211 & 102.09 & 137.91 \\
\hline Aqueous & $114.00(-47.22 \%)$ & 6.000 & 99.10 & 128.90 \\
\hline
\end{tabular}

LB, Lower bound; UB, Upper bound 


\section{Macrothink}

Table 3.3: Effects of two weeks of oral administration of various solvent extracts of rhizome part of P. emodi on serum AST level of mice with PCM induced hepatotoxicity

\begin{tabular}{|c|l|c|c|c|}
\hline Groups & Mean & SD & \multicolumn{2}{c|}{ 95\% Confidence interval } \\
\cline { 4 - 5 } & & & Lower Bound & Upper Bound \\
\hline Negative control & 8.0 & 2.58 & 4.91 & 11.64 \\
\hline Negative control & 30.33 & 4.509 & 19.13 & 41.53 \\
\hline Standard & $17.00(-43.94 \%)$ & 5.000 & 4.58 & 29.42 \\
\hline Crude & $13.00(-57.13 \%)$ & 5.000 & .58 & 25.42 \\
\hline Chloroform & $10.33(-65.94 \%)$ & 2.082 & 5.16 & 15.50 \\
\hline Butanol & $12.00(-60.43 \%)$ & .000 & 12.00 & 12.00 \\
\hline Aqueous & $13.00(-57.13 \%)$ & 2.646 & 6.43 & 19.57 \\
\hline
\end{tabular}

M, Mean; SED, Standard deviation of means

Table 3.4: Comparison of the hepatoprotective effects of various solvent extracts of rhizome part of P.emodi in mice with PCM induced hepatotoxicity

\begin{tabular}{|c|c|c|c|}
\hline \multirow[t]{2}{*}{ Groups } & \multicolumn{3}{|c|}{ Liver Enzymes } \\
\hline & ALT & AST & ALP \\
\hline Normal control & $15.25^{\mathrm{e}} \pm 3.3$ & $8.0^{\mathrm{bcd}} \pm 2.58$ & $64.75^{\mathrm{f}} \pm 5.7$ \\
\hline Negative control & $203^{a} \pm 10$ & $30.33 \pm^{\mathrm{a}} 4.509$ & $216.00 \pm^{\mathrm{a}} 10.00$ \\
\hline Standard & $126.0 \pm{ }^{\mathrm{b}} 5$ & $17.00 \pm \pm^{\mathrm{b}} 5.00$ & $171.00 \pm{ }^{\mathrm{b}} 6.00$ \\
\hline Methanol & $110.67 \pm^{\mathrm{bc}} 5.51$ & $13.00 \pm{ }^{\mathrm{bc}} 5.00$ & $141.00 \pm \pm^{\mathrm{c}} 7.00$ \\
\hline Chloroform & $104.0 \pm{ }^{c} 5$ & $10.33 \pm^{\mathrm{bcd}} 2.082$ & $126.33 \pm^{\mathrm{cd}} 5.132$ \\
\hline Butanol & $80.67 \pm{ }^{\mathrm{d}} 6.50$ & $12.00 \pm{ }^{\mathrm{bc}} 0.00$ & $120.00 \pm{ }^{\mathrm{de}} 7.211$ \\
\hline Aqueous & $79.0 \pm \pm^{\mathrm{d}} 5.00$ & $13.00 \pm \pm^{\mathrm{bc}} 2.646$ & $114.00 \pm{ }^{\mathrm{de}} 6.00$ \\
\hline
\end{tabular}

PCM, Paracetamol

\section{Discussion}

During the present study, hepatotoxicity was induced through oral administration of high dose of paracetamol. Paracetamol intoxicated mice revealed significantly increased AST, ALT and ALP activities $(<0.05)$ when compared with the healthy controls. The sharp increase in serum ALT level is considered to be a significant indicator of PCM-induced acute liver damage (Thapa and Walia, 2007). Alanine transaminase (ALT) is an enzyme specific to liver damage. The present study demonstrated a significant increase in the serum ALT levels of PCM-intoxicated mice, which signifies PCM-induced acute liver damage to have developed. During the present study PCM-intoxication also resulted in increased levels of serum AST and ALP. Serum AST and ALP levels also increase due to damage to various other tissues and organs. Acute PCM intoxication in experimental animals results in elevated levels of serum AST and ALP in addition to ALT levels (Thapa and Walia, 2007). 
Paracetamol is a drug of the para-aminophenol group, which is considered quite safe at recommended doses and is commonly used in humans to relieve mild to moderate pain, as well as to reduce fever (Meotti et al., 2006). The main problem with this medication is misuse through intentional or unintentional ingestion of supratherapeutic dosages, which usually lead to hepatic necrosis. When administered at normal doses, PCM is primarily metabolized by conjugation with sulfate and glucuronic acid. A minor pathway through CYP450 has been also reported to yield a highly reactive metabolite, $\mathrm{N}$-acetyl-p-benzoquinone imine (NAPQI). This metabolite is generally stabilized through conjugation with glutathione (GSH) and eliminated via the kidney. However, when an overdose of PCM is administered, the production of NAPQI overloads the capacity of GSH to detoxify it. The excess NAPQI then causes liver damage associated with oxidative stress (Ojo et al., 2006).

In the present study, the hepatic cellular injury might be due to increasing oxidative stress that leads to lipid peroxidation. Lipid hydroperoxides are byproducts of lipid peroxidation and increased levels of lipid peroxidation products are associated with a variety of chemical-induced toxicities including PCM (Choi et al., 2010; Yousef et al., 2010). Lipid peroxidation products are known to cause cellular injury by inactivation of membrane enzymes and receptors, depolymerization of polysaccharide, as well as protein cross-linking and fragmentation (Luqman and Rizvi, 2006). It has been reported that lipid peroxidation products increase in the liver tissues of paracetamol intoxicated mice (Kanbur et al., 2009).

Damage to the membranes of liver cells and organelles, cause the swelling and necrosis of hepatocytes and result in the release of cytosolic enzymes such as Alanine transaminase (ALT), Aspartate transaminase (AST) and Alkaline phosphatase (ALP) into the blood circulation (Madhumitha et al., 2010).

During the present research, the mice with paracetamol-induced hepatotoxicity were treated with a standard antioxidant drug, Silymarin, and various solvent extracts of the rhizome of $P$. emodi for two weeks. During the two week treatment period the drug and plant extracts showed ameliorative activities as evident from the significant reduction in the serum levels of ALT, AST and ALP in drug and extracts treated mice when compared with mice that received PCM $600 \mathrm{mg} / \mathrm{kg}$ body weight but not treated with drug or extracts. Silymarin decreased the levels of ALT, AST, and ALP but not as effectively as the plant extracts in attenuation of hepatotoxicity caused by PCM. The significant decrease in the serum levels of ALT, AST and ALP in drug and plant extracts treated animals might be due to decreased leakage from the liver cells. The observed hepatoprotective effect might be a consequence of the amelioration of oxidative stress and maintenance of the antioxidant capacity conferred by the drug and plant extracts. Treatment with drug and extract resulted in the suppression of the leakage of ALT, AST, and ALP into blood circulation. This suggests that the plant extracts possessed the potential of repairing the hepatic injury and restoring the cellular permeability. The extracts were able to reduce the toxic effect of paracetamol in the liver tissues.

The hepatoprotective effects of plants are attributed to the presence of flavonoids, ascorbic acid, carotenoids, phenolic compounds (Hu et al, 1965), Tannins and lignins (Greger and 
Hofer, 1980) among the plant constituents. The flavonoids are known to be antioxidant (Faure et al., 1990), free radical scavengers (Bors and Saran, 1987) and anti-lipo per oxidant leading to hepatoprotection (Handa et al., 1986). Similarly ascorbic acid serves as an anti-oxidant (Bus and Gibson, 1984) and consequently can minimize the toxic effect to the liver (Harman, 1985). Moreover, carotenoids are also reputed to be antioxidant and thus showing antihepatotoxic activity. Phenolic compounds are reported to have antioxidant and free radical scavenging potential (Zhou and Zheng, 1991) and can prevent peroxidative damage to biomembranes in hepatocytes (Liu et al., 1992). Furthermore, the hepatoprotective activity of tannins as well as lignans (Faure et al., 1990) is also well documented.

\section{Conclusion}

Plants and their extracts are well known for a number of chemicals belongs to different classes. The chemicals such as flavonoids, steroids, triterpenoids and their glycosides, alkaloids etc, are well known for their pharmacological importance. The results of the study revealed that the present research concluded that methanol, chloroform, butanol and aqueous extracts of the rhizome part of Paeonia emodi have the potential to reduce paracetamol-induced hepatotoxicity in mice and have potential to restore the normal liver function. Current findings of the study authenticated the ethnomedicinal value of the plant Paeonia emodi used in the treatment of liver diseases like hepatitis etc. Furthermore, a broad analysis of bioactive components of the fractions is needed to justify the active principle(s), to assess the efficacy and toxicity in various mechanisms of action for producing it as a protective and effective herbal hepatoprotective drug.

\section{Conflict of Interests}

The authors have not declared any conflict of interests.

\section{References}

Afonja JP, Baron DN (1974). Plasma alkaline phosphatase isoenzymes in hepatobiliary disease. Journal of Clinical Pathology, 27: 916-920.

Almo SC, Smith DL, Danishefsky AT, Ringe D (1994). "The structural basis for the altered substrate specificity of the R292D active site mutant of aspartate aminotransferase from E. coli". Protein Enginering., 7 (3): 405-412.

Basu S, Haldar N, Bhattacharya S, Biswas S and Biswas M (2012). Hepatoprotective Activity of Litchi chinensis Leaves Against Paracetamol-Induced Liver Damage in Rats. American-Eurasian Journal of Scientific Research., 7 (2): 77-81.

Bors W, Saran M (1987). Radical scavenging by flavonoid antioxidants. Free Radical Research Communication Journal., 2: 284-294.

Brown RA (1997). Digestive System Liver. Colorado State University.

Burkitt HG, Young B, Heath JW (1997). Wheater's Functional Histology. New York Churchill Livingston., 407. 
Bus JS, Gibson JE (1984). In Drug metabolism and drug toxicity. Ed. By J.R. Mitchel and M.G. Horning, Raven Press, New York., 21-32.

Choi KC, Chung WT, Kwon JK, Yu JY, Jang YS, Park SM (2010). Inhibitory effects of quercetin on aflatoxin B1-induced hepatic damage in mice. Food Chemical Toxicology., 48: 2747-53

Faure M, Lissi E, Torres R, Vidella LA (1990). Antioxidant activities of lignin and flavonoids. Phytochemistry journal, 29: 3773-3775.

Friedman LS, Martin P, Munoz SJ (1996). Liver function tests and the objective evaluation of the patients with liver disease. Journal of Hepatology., 791-833.

Ghosh J, Das J, Manna P, Sil PC (2010). Acetaminophen-induced renal injury via oxidative stress and TNF-alpha production therapeutic potential of Arjun eolic acid. Toxicology., 268, 8-18.

Greger H, Hofer O (1980). New unsymmetrical substituted tetrahydro furfuran lignan from Artemisia absinthium. Assignment of the relative Stereochemistry by Lanthanide induced chemical Shifts. Tetrahedron., 36: 3551-3558.

Guyton AC, Hall JE (1996). Textbook of Medical Physiology. Philadelphia: Walter Burns. Saunders Company., 1148.

Handa SS, Anupam S, Chakraboratikk (1986). Natural products and plants as liver protecting drugs. Journal Fitoterapia ., 57: 307-351.

Harman AW (1985). The effectiveness of antioxidants in reducing paracetamol-induced damage subsequent to paracetamol activation. Research Communication Chemical Pathology Pharmacology., 49: 215-228.

Himmerich H, Anghelescu I, Klawe C, Szegedi A (2001). Vitamin B 12 and Hepatic enzyme levels correlate in male alcohol dependent patients. Alcohol \& Alcoholism., 36 (1): 26-28.

Hu JS, Li PC, Chen M (1965). Choleretic principles of Artemisia scoparia I. Water-soluble fraction of its extract. Journal of Engineering Thermophysics., 12: 289-294.

Hurkadale JP, Shelar AP, Palled GS, Mandavkar DY, Khedkar SA (2012). Hepatoprotective activity of Amorphophallus paeoniifolius tubers against paracetamol-induced liver damage in rats. Asian Pacific Journal of Tropical Biomedicine., S238-S242.

Jaeschke H, Knight TR, Bajt ML (2003). The role of oxidant stress and reactive nitrogen species in acetaminophen hepatotoxicity. Toxicology Letters., 144: 279-88.

Kanbur M, Eraslan G, Beyaz L, Silici S, Liman BC, Altinordulu S (2009). The effects of royal jelly on liver damage induced by paracetamol in mice. Experimental Toxicological Pathology., 61: 123-32.

Kataki SM, Murugamani V, Rajkumari A, Singh P, Mehra SP, Awasthi D, Yadav SR (2012). Antioxidant, Hepatoprotective, and Anthelmintic Activities of Methanol Extract of Urtica 
dioica L. Leaves. Pharmaceutical Crops., 3: 38-46.

Kechrid Z, Kenouz R (2003). Determination of alkaline phosphatase activity in patients with different zinc metabolic disorders. Turkish Journal of Medical Science., 33:387-391.

Khan T, Ahmad M, Nisar M, Ahmad M, Lodhi MA, Choudhary MI (2005). Enzyme inhibition and radical scavenging activities of aerial parts of Paeonia emodi Wall. (Paeoniaceae). Journal of Enzyme Inhibition and Medicinal Chemistry ., 20(3): 245-249.

Liu GT, Zhang TM, Wang BE, Wang YW (1992). Protective action of seven natural phenolic compounds against peroxidative damage to biomembranes. Biochemical Pharmacology., 43: 147-152.

Luqman S, Rizvi SI (2006). Protection of lipid peroxidation and carbonyl formation in proteins by capsaicin in human erythrocytes subjected to oxidative stress. Phytotherapy Research., 20: 303-306.

Madhumitha G, Saral AM, Senthilkumar B, Sivaraj A (2010). Hepatoprotective potential of petroleum ether leaf extract of Crossandra infundibuliform on $\mathrm{CCl} 4$ induced liver toxicity in albino mice. Asian Pacific Journal Tropical Medicine ., 3(10): 757-840.

Meotti FC, Rosa JM, Brocardo PS, Balz D, Waltrick AP, Bagio A (2006). Protective effect of crude extract from Wedelia paludosa (Asteraceae) on the hepatotoxicity induced by paracetamol in mice. Journal Pharmacy and Pharmacology., 58: 137-42.

Muhammad P, Ahmad S, Rubnawaz H, Ullah N, Malik A (1999). New monoterpene glycosides from Paeonia emodi. . Journal of Chemical Sciences ., 54: 544 -548.

Nalpas B, Vassault A, Charpin S, Lacour B, Berthelot P (1986). "Serum mitochondrial aspartate aminotransferase as a marker of chronic alcoholism, diagnostic value, and interpretation in a liver unit". Journal of Hepatology., 6 (4): 608-612.

Nawaz HR, Malik A, Khan PM, Shujaat S, Rahman A (2000a). A novel glucuronidase inhibiting triterpenoid from Paeonia emodi. Chemical and Pharmacological Bulletin ., 48(11): 1771-1773.

Patel JA, Shah US (2009) Hepatoprotective activity of Piper longum traditional milk extract on carbon tetrachloride-induced liver toxicity in Wistar rats. Latin American and Caribbean Bulletin of Medicinal and Aromatic Plants., 8(2): 121-129.

Rashed K, Chang CW, Wu LY, Peng HW (2013). Hepatoprotective Effect of Cestrum parqui L. aerial parts and phytochemical profile. World Journal of Pharmaceutical Sciences., 2321-3310.

Riaz N, Anis I, Rehman A, Malik A, Ahmed Z, Muhammad P, Shujaat S, Rahman A (2003). Emodinol, a B-glucuronidase inhibiting triterpene from Paeonia emodi. Natural Product Research., 17(4): 247-251.

Rubab A, Hemamalini K, Priya SG, Vasireddy U (2013). Hepatoprotective Activity of Gymnosporia emerginata (Wild) and Marsdenia volubility (Linn.F) Stapf against 


\section{Macrothink}

Paracetamol Induced Hepatotoxicity in Rats. International Journal of Current Pharmaceutical Review and Research., 4(2): 36-41.

Samal KP (2013). Hepatoprotective activity of Ardisia solanacea in CCl4 induced hepatotoxic albino rats. Asian Journal of Research Pharmaceutical Science., 3: 79-82.

Thapa BR, Walia A (2007). Liver function tests and their interpretation. Indian Journal of Pediatrics ., 74: 663-671.

Tillyer CR, Rakhorst S, Coley MC (1994). Multi-component analysis for alkaline phosphatase isoenzymes determination by multi-linear regression. Clinical Chemistry., 40: 803-810.

Yousef MI, Omar SA, El-Guendi MI, Abdelmegid LA (2010). Potential protective effects of quercetin and curcumin on paracetamol-induced histological changes, oxidative stress, impaired liver and kidney functions and haematotoxicity in the rat. Food Chemical Toxicology., 48: 3246-61.

\section{Copyright Disclaimer}

Copyright for this article is retained by the author(s), with first publication rights granted to the journal.

This is an open-access article distributed under the terms and conditions of the Creative Commons Attribution license (http://creativecommons.org/licenses/by/3.0/). 